\title{
Assessing Ongoing Electronic Resource Purchases: Linking Tools to Synchronize Staff Workflows
}

\section{Running Title: Assessing Ongoing Electronic Resource Purchases}

\author{
Jeffrey D. Carroll \\ Colleen Major \\ Nada O’Neal \\ John Tofanelli
}

This is the pre-publication version of a paper published in the Journal of Electronic Resource Librarianship (JERL) (V.24, Issue 2, April 2012, pp. 79-90)

ISSN: 1941-1278

\begin{abstract}
Ongoing electronic resource purchases represent a substantial proportion of collections budgets. Recognizing the necessity of systematic ongoing assessment with full selector engagement, Columbia University Libraries appointed an Electronic Resources Assessment Working Group to promote the inclusion of such resources within our current culture of assessment. This article describes the Working Group's implementation of an electronic resource renewal reminder system in Google Calendar, a calendar already in use by selectors for daily scheduling. In discussing this particular solution, this article shows how libraries can link existing systems together to move beyond their limitations and integrate them into existing staff workflows.
\end{abstract}

Keywords: Electronic resources assessment, electronic resources evaluation, electronic resource management systems, Google Calendar, middleware

Jeffrey D. Carroll is Assistant Director for Collection Development, Columbia University Libraries; Colleen Major is Electronic Resources Librarian, Columbia University Libraries; Nada O'Neal is Senior Systems Engineer, Columbia University Libraries; and John Tofanelli is Librarian for British \& American History \& Literature, Columbia University Libraries. Address correspondence to Jeffrey D. Carroll, Columbia University, 507A Butler Library, 535 West $114^{\text {th }}$ St., New York, NY 10027. E-mail: jc677@columbia.edu 


\section{Assessing Ongoing Electronic Resource Purchases: Linking Tools to Synchronize Staff Workflows}

\section{Running Title: Assessing Ongoing Electronic Resource Purchases}

Among university libraries reporting to ARL, median expenditures for ongoing electronic resource purchases accounted for 51.9\% of total materials budgets in 2008-2009 (ARL Statistics 2008-09). The category of ongoing electronic resource purchases, as defined by ARL, includes both subscription expenditures and annual access fees for one-time purchases. This category does, in fact, match a concept that is already very real in the minds of all those who manage library materials budgets. When making any electronic resource purchase decision, librarians must consider, on the one hand, its impact on the current fiscal year, and, on the other, its ongoing impact on future fiscal years if access is to be maintained. Some libraries, such as Columbia, even utilize distinctive fund codes for all electronic resource expenditures that are ongoing in nature in order to facilitate tracking and analysis of expenditure patterns.

Ongoing purchases in any format have always required monitoring, planning, and foresight. Since they are cumulative in nature, they could potentially overwhelm the materials budget as a whole and thus compromise our ability to acquire new resources. Because of such dangers it would seem that assessment should always have gone hand in hand with the maintenance of ongoing materials expenditures. Yet we know that this has not been the case. Assessment of ongoing purchases has always been challenging and time consuming. At many institutions it has most typically been undertaken in the form of serials cuts, a familiar response to situations of fiscal crisis. At this point in the history of library materials budgets, we might consider that all of us are to varying degrees, and especially with regard to ongoing electronic resource purchases, in states of fiscal crisis. Materials budgets have tended in recent years, either to flatten or to increase only minimally, whereas the price of electronic resources, on the other hand, has continued to increase. Thus in some regards the current need for assessment does fall within the parameters of the crisis / response model already familiar to us from our collective experience with serials cuts. 
There are a number of reasons, however, why we need, in an electronic resources environment, to move beyond the familiar crisis / response model of assessment to something that is more holistic, regularized, and supportive of the health of our collections. Firstly, many core databases are available on multiple different platforms. Thus we do have the option of switching a database to a new platform rather than renewing them faithfully on the old. Such a switch may result in cost savings, enhanced functionality, or both; but such a switch should never be made without careful preparatory assessment work. Secondly, we are faced with the challenge of maintaining uninterrupted access to the resources we have paid for. Data that calls our attention to access problems comes from many directions; and assessment is one of those directions. Some of the puzzles uncovered in the consideration of usage data, for example, can point to problems that need to be investigated and resolved. Why, for example, does the data show turnaways for one month out of twelve when the database in question has no user limits? When a journal shows sustained zero usage, is it because it is unpopular or because the relevant link is omitted from our OPAC record? Assessment needs to be seen, therefore, as something more than a prelude to cancellation vs. retention decisions. It is also a key part of the process whereby the optimal health and value of the libraries' electronic resource collections is ensured.

Libraries have far more assessment-related information available to them today than they did a decade ago. COUNTER standards (first released in 2002 and most recently revised in 2008) have defined precisely what is being measured in usage statistics. Those standards work to ensure that the numbers supplied by one COUNTER-compliant vendor are truly comparable to those supplied by another. Electronic Resource Management Systems (ERMS) further make it possible to generate consolidated reports, in which the usage data supplied by one vendor is compared with the usage data supplied by others, and to arrive at cost-per-use calculations.

The mere existence of information, however, does not guarantee that it will be put to use. A recent survey identified "workflow or communications management" as the top priority area of concern for academic librarians in the area of electronic resource management and also as "one of the biggest 
deficiencies (and disappointments)" in functionality of currently available ERMS (Grogg and Collins, 2011, p. 23). In the process of making assessment data available to selectors at Columbia Libraries, we discovered that a great deal depends not simply on what information is made available to selectors, but on how it is made available.

At Columbia, an Electronic Resources Assessment Working Group was appointed in 2009 to take stock of the assessment information sources available and to foster the employment of such sources through education and outreach. Our Working Group reports to our Collections Steering Committee and includes selectors from key disciplinary areas, a representative from our Continuing and Electronic Resource Management Division, and our Assistant Director for Collection Development. One part of our charge has been to integrate librarian selectors more systematically in the workflow of subscription-based electronic resources assessment.

At libraries with a relatively small number of ongoing electronic resource purchases, it might be possible to implement one centralized procedure and one established time frame for their annual assessment, such as that described in England and Fu, 2011. At Columbia, however, we have 126 funds dedicated to such purchases, with a total of $\$ 10,568,113$ spent on them in 2008-2009. Renewal invoices are received throughout the fiscal year. Furthermore, we have more than forty staff members with selection responsibilities. We could not, therefore, implement any single centralized procedure, time frame, or workflow for the assessment of ongoing electronic resource purchases. We needed first to understand what selectors were already doing, or not doing, and then try to facilitate and inspire a culture in which assessment was perceived as an ordinary aspect of collection management workflow.

In beginning our work, we found across the library system a very uneven landscape in terms of assessment practices. Science librarians, for example, had long been accustomed to analyzing usage data and in basing renewal decisions for electronic journal titles on the results of such analysis. Typically science librarians analyzed usage data obtained directly from vendors. They tended to make limited use of usage data as harvested into standardized and/or consolidated reports by our ERMS. Librarians in the humanities and social sciences on the other hand, tended to be less familiar with the concept and the 
potential value of usage data. For them the reports as presented by our ERMS were a valuable starting point, making it easier to move from one vendor's data to another's without having to negotiate each vendor's Web site. Both groups of librarians, however, found the overlap analysis tool (which compares databases in light of duplicate and unique coverage for full text journals) in our ERMS to be helpful.

Given the diversity of experience and approach our Working Group has aimed to create a more cohesive assessment culture. On the one hand, science librarians with substantial assessment experience became an important presence within the Working Group, helping the rest of us to better understand concepts that they had long been employing. They also became important emissaries for change describing the process and results of large scale assessment projects at selectors' meetings and at meetings of our Collections Steering Committee. On the other hand, we also chose to emphasize some of the most accessible assessment-related tools so that even librarians relatively inexperienced in the assessment process could feel some sense of ownership and involvement in a common purpose that our library system was supporting.

One of those accessible assessment-related tools was, in fact, created by teamwork between our Electronic Resources Assessment Working Group and our Library Information Technology Office--a series of fund calendars in Google Calendar. These calendars tracked all transactions taking place on funds used to support ongoing electronic resource purchases, and provided staggered reminders of when the next renewal would take place. This article describes our need for such a reminder system, the process of its implementation, and the publicizing of the calendars to library selectors. 
Figure 1. Google Calendar with month view.

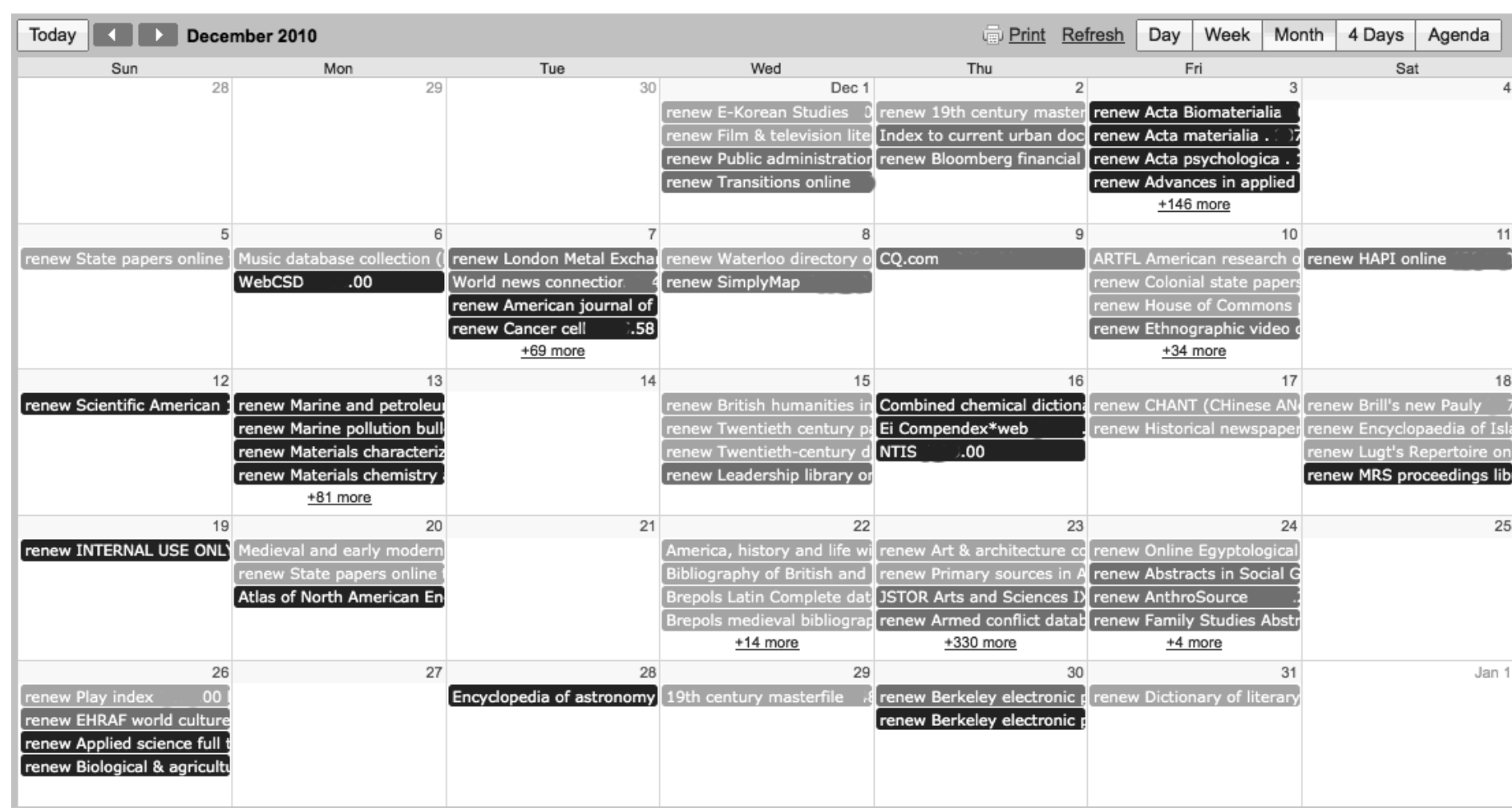

\section{Prior to Google Calendar}

Before the implementation of our renewal reminder system, subject selectors would need to log into our local Voyager acquisitions system or use the regular biweekly export of data from the Voyager Integrated Library System in order to view purchase information details. The export scripts were themselves the result of an earlier local development effort to consolidate disparate pieces of information into a single report in HTML or Excel. The reports are widely used and are well-received by users, primarily selectors who want to explore and manipulate fund activity data. While this data was very useful, it was passive and did not help shape the renewal decision-making process. Selectors managed their renewal schedules, if any, independently and had to proactively seek information relevant to those renewals. 
Desiring to automate and standardize an informative alerting system, the local Electronic Resource Assessment Working Group launched an investigation into local systems that could be used. Our local ERMS (Serials Solutions 360 Resource Manager) was reviewed for potential push technologies. Our ERMS does allow for some alert functionality. Three alerts can be created in our local ERMS: alerts on resource status, global status and license status. The alert with the most promising functionality was based on license advance notice date. However, this would not work for us. The ERMS requires any license data to be input manually. In addition to not having entered necessary data in many cases, alerts could not be set up from cost data within our ERMS. Our licenses are sometimes multi-year commitments that don't coincide with the renewal cycle. The most reliable date to use for a renewal alert feature would be the date that the last invoice was paid, but an alert generated from that data was not available in the ERMS.

When it became clear that our ERMS would not allow the alert functionality that we were hoping for, the Working Group began to look at other possibilities. After reviewing the Voyager exports, it became clear that they already had most of the data necessary for informative, timely alerts. Since they were developed in-house, they could be adjusted as necessary to include additional data, as described below. All that was necessary was to identify and implement a sufficiently robust and customizable alerting system that could import that existing data.

\section{Choice and Implementation of Google Calendar}

Google Calendar was a natural choice for an alerting system at Columbia Libraries. As Northwestern University Library discovered in implementing their own ERMS, it is important to "think locally" and consider issues like staff familiarity and existing workflows. (Gustafson-Sundell, 2011) The Libraries had recently switched to Google Calendar for staff calendaring, and there were no major policy, access, user, or technical barriers to its use at our institution. Within the past year, the Libraries had contracted with Google for a private domain account, meaning that our domain's data had certain protections beyond a normal google.com consumer account, and we were authorized by the University to use it for all staff record-keeping purposes. All staff were already provisioned with an account on our domain, and many staff were "power users", comfortable with advanced functions. The transition to Google Calendar, 
involving hundreds of hours of technical staff time, had taken place within the past six months, so many staff had recently attended a training session or read internal documentation. Additionally, the technical staff had already written administrative scripts against Google's application programming interface (API), so automating resource renewal alerts seemed possible, and existing in-house expertise could attack the problem.

In December 2010 when library information technology staff began addressing the issue of resource renewal reminders, Montclair State University had already documented its use of Google Calendar for the same purpose. (Shapiro S, 2010) Montclair's situation was slightly different from Columbia's: it was practical for a few librarians to enter all the renewal data by hand, and only a few staff needed to receive reminders. Therefore, the staff provisioning and APIs that were so essential in our case were not necessary at Montclair. ERAWG staff had originally expected that Columbia techs might be able to, annually or bi-annually, manually import fund text export data into Google Calendar. However, due to the number of fund codes at Columbia, this middle option still required hours of manual labor, and would only have been used if Columbia's chosen calendar had not been scriptable.

Interestingly, Montclair had rejected other software solutions because they might require "a programmer or systems specialist who is comfortable working with open source software and operating systems like LINUX or UNIX.” (Shapiro, 2010) Montclair had chosen Google Calendar precisely because it was possible to use it effectively without extensive technical resources - practically the opposite of Columbia's requirements. Our experience shows that even institutions burdened with extensive library management infrastructure and technical teams can benefit from Google Calendar. Once the data is entered in to Google Calendar, whether by a script using the hidden APIs or by a Librarian using the web interface, Google Calendar provides the same reminder or altering options.

Google Calendar, considered simply as an alerting system, is quite robust. Each Google Calendar user can set her own alert options by calendar or by event. Calendars can even be shared across institutions, or with any Google user - for example, with a librarian at a partner institution maintaining a complementary collection. At Columbia, each fund code was given its own calendar, so staff could subscribe to the fund 
codes they managed and set their preferred alerts. As Monclair State University noted, Google Calendar will only allow alerts up to four weeks in advance of an event. (Shapiro, 2010) Columbia implemented essentially the same workaround as Montclair, populating the calendars with multiple events per purchase: an event for the initial purchase, an event for a five-month expiration alert, and an event for a three-month expiration alert. (There is no event, in Columbia's implementation, for the expected expiration date.)

Columbia's technical staff were able to implement this alerting system relatively easily, with about five hours spent drafting and testing the original script, and another ten to fifteen spent adjusting it in response to user feedback and developing supplemental utility scripts. A few minutes each week are needed to check logs and improve the script as needed. However, this light implementation burden was only possible because of the extensive technical work already done, implementing Google Calendar and developing data exports from Voyager. Institutions that don't have a similar alerting/time-tracking system available, or that haven't begun the work of data consolidation, should estimate significantly more staff time. Institutions that currently use other time-tracking, workflow, calendar, or alerting systems may wish to employ their existing system for resource renewal alerts, assuming it can be scripted or can bulk import data. Although this section will delve into Google-specific implementation details, we hope it is general enough to interest institutions using other systems as well.

\section{Obtaining the Electronic Resource Purchase Data}

Columbia's script, written in python and available online (Carroll et al, 2011), gathers its data from exports produced from the Voyager library management system. These exports, described previously, are produced by perl scripts that run independently of the python import script, and consist of one directory per fund code, containing comma-separated value (text) data for purchases made against that fund in the previous year. At other institutions, it might make sense to combine the export and import into a single script or set of scripts. At Columbia, however this wasn't immediately practicable - the expertise required to gather the data from Voyager is extensive, and the programmer who developed the exports was not experienced in writing against the Google API, and the Google API programmer was not at all 
knowledgeable about the Voyager system. Furthermore, these fund reports had been carefully crafted over the course of many years to serve a variety of purposes - electronic resource renewals are a relatively minor function. These staffing and use disconnects, however, opened the way to write the Voyager export and Google API import in optimal languages for each, and allowed the scripts to be independently scheduled, which has its own advantages.

The export from Voyager is tied to institutional purchasing schedules, and is accomplished in a massive, uninterrupted export to a local server twice per month. The Google import is run against a web API, so timeouts and interruptions are common. The import script was designed to be elastic, to be halt and re-start non-destructively, to continue processing additional events if there is a problem entering one, to be able to run over and over again without creating duplicates. The script runs weekly against year-long cumulative files per fund code, checking each purchase against the events on the calendar, and filling in missed events if needed. The script produces a log of failures, which is checked for outlier errors, events from a month or more prior that have repeatedly failed to be entered. Because the first alert (5 months until expiration) occurs seven months after purchase date, there is ample time to resolve any entry errors. Although it may sound inefficient to check every purchase from the previous on every script run, this circumspection insures that no event is missed. Even an end-of-year run, with over a hundred fund codes with hundreds of events each, takes less than 20 minutes. Google has daily API upload limits, and during testing, when an entire year's worth of event data needed to be uploaded, these limits were sometimes reached. However, the limits aren't taxed by checking for the existence of events.

\section{Creating and Updating the Fund Code Calendars}

Columbia University Libraries Morningside campus has 1,260 allocated funds in our current 2011 Ledger, 126 of which are associated with recurring electronic expenditures, though this list may change with every Voyager export. The relevant codes can only be identified by their code suffix, "E" or "EO". Every time the import script runs, it compiles a list of all the directories that match this pattern. This list 
of matching directories is compared against the list of existing fund code calendars. Any new calendars are created.

The new calendars are created in and owned by a calendar service account, but are shared with the entire Columbia Libraries Google domain. The calendars are titled simply with the name of the fund code, and then are added to the domain-wide Google address book as "Fund Code [name]". This allows any staff member of the Libraries to easily find the codes that interest them; staff are not subscribed automatically. Without the ability to share with the domain, we would have had to find a way to query a list of staff associated with each fund code, and share piecemeal. Additionally, the script would have had to revise existing calendar sharing settings as staff were hired, added to projects, or transferred to new positions. As a matter of policy, too, all Voyager fund code exports have always been available to all staff, so it was most consistent to share the fund code reminder calendars in the same way.

After creating the new calendars, the script's list of current fund code calendars is revised. For each existing fund code calendar, the script expects to find a directory of the same name. Assuming it does, the script reads the file of cumulative purchase events and adds any new events, plus their associated reminders. Because there are no unique identifiers associated with individual resource renewals (there may be several on a single purchase order), the entire line from the csv file is used as the unique identifier, and pasted as-is, in the description. In the unlikely event that a previous purchase event changed, a "duplicate" event would be created. However, this "duplicate" would alert the person subscribed to the calendar that something unusual had happened and needed to be investigated.

If the script does not find a directory for an existing fund code calendar, it logs an error, but continues. Fund codes drop out of use sometimes, in which case the script would continue to log an error until the calendar was manually deleted. This behavior ensures that a file system, export, or permissions error will not silently prevent a fund code calendar from being updated. 


\section{Calendar Clean Up and Errors}

Two utility scripts were needed during the development of the import script - one to find calendars without an address book entry, and one to empty selected fund code calendars of all events. These scripts, as well as one to list all fund code calendar subscribers, are also available online. (Carroll et al, 2011)

It's possible for the script to successfully create a fund code calendar, but fail on the independent step of adding the calendar to the global address book. In that case, the calendar cannot be found by Library staff, regardless of whether future runs of the script populate it with events. So this script, which is run regularly, looks for calendars owned by the service account that have a fund code title but are missing an associated address book entry. All such calendars are deleted, regardless of whether they have any data. (Any data that should be in the calendar will be added again at the next run of the import script. No staff will be affected by this deletion because they have had no way to find the calendar.)

The script to empty existing calendars of all events was necessary in the early days of development when the script would sometimes create duplicates, and when Electronic Resource Assessment Working Group were experimenting with different options for displaying information within the events. It may also be useful in the future if there is an error in the Voyager export script that introduces a change into existing lines of the fund code export files. If that happens, the affected fund codes will be full of duplicate events. Although we could delete entire calendars, and have the script remake them, this would force staff to re-subscribe and set new reminder preferences. Emptying the calendars and re-populating them preserves all staff settings.

\section{Google Calendar Use Changes the Voyager Exports}

After a small amount of testing of the Google-based reminder system, Electronic Resource Assessment Working Group staff quickly identified some additional data that selectors would need to make informed renewal decisions. Specifically, the Working Group asked that the Vendor Name be included instead of the Voyager ILS vendor code, because the name would be immediately recognizable to selectors. The contents of the notes field from the purchase order or invoice were also added because these often contained information key to understanding the nature of the payment transaction. The Voyager 
programmer was able to pull in this additional data, which required querying new areas within the Voyager system. In order to not disrupt the current users of the exports, the programmer appended this new information to the end of the data line within the CSV export.

\section{Publicizing Google Calendar as a tool to Selectors}

After several iterations of testing, modifying and tweaking, the group deemed the Google fund calendars ready for use. At this stage selectors were mostly unaware of efforts to develop such a tool, so it became incumbent on the group to introduce the tool in conceptual terms at first, to describe why it was necessary in the first place, and how it might be put to practical use. This began simply enough by making a broad announcement via email, and distributing a document which described the system and its potential applications. This document was presented in a Frequently Asked Questions format and included the following: Which funds have fund calendars? What information is contained in fund calendars? How do I access a fund calendar? What is the purpose of accessing fund calendars? Which fund calendars should I look at? Instructions and examples were included in the answers to these questions. In addition, selectors were encouraged to start experimenting with the new tool. This was followed by a demonstration at the monthly meeting of the Selectors' Discussion Group in November 2010. As a follow-up, selectors were asked to subscribe to at least one fund calendar prior to a subsequent meeting of the Selectors' Discussion Group the following February.

During the demonstration in November, the Working Group led a discussion that clarified the power of Google fund calendars as a tool that provided simple date-based access to renewal information. The current system, it was reiterated, was simply a reactionary one that typically relied on the arrival of an invoice - due within thirty days - to alert us that any given resource was due for renewal, thereby allowing no time for thorough evaluation and, in most cases, already beyond the notification period stipulated in many license agreements. The Google fund calendars would give us the ability, for the first time, to anticipate renewals as much as five months in advance. Selectors were then shown how to subscribe to fund calendars of their choice, how to find all the resources associated with a particular fund by using the "Agenda" view (see Figure 2), and how to search for dates associated with specific resources on a given 
fund, or across a group of funds, by searching the calendar for the resource name. (see Figure 3) Selectors were also shown examples of the data contained in each event (described in Section II), how they could load the events into their own calendars and how to set reminders for the events. It was also pointed out that the fund calendars should form an integral part of a larger process by which a selector tracks and assesses the electronic resources for which she or he is responsible.

Figure 2. Agenda view.

Mon Dec 6,2010 All day $\quad$ Music database collection (RILM, RIPM, RISM, IPM Music C

Tue Dec 7, $2010 \quad$ All day $\quad$ World news connection $\quad 44$

All day $\boxplus$ renew London Metal Exchange .00 by $03 / 08 / 2011$

Wed Dec 8,2010 All day $\boxplus$ renew Waterloo directory of English newspapers and peric All day $\quad \boxplus$ renew SimplyMap $\quad 50$ by $05 / 10 / 2011$

Thu Dec 9,2010 All day $\boxplus$ CQ.com $\quad .00$

Fri Dec 10,2010 All day $\quad \pm$ renew Ethnographic video online $\quad .00$ by $05 / 12 / 2011$

All day $\quad \boxplus$ renew House of Commons parliamentary papers _ j.00 b

All day $\quad \pm$ renew Colonial state papers _...00 by $05 / 12 / 2011$

All day $\quad \Phi$ ARTFL American research on the treasury of the French le

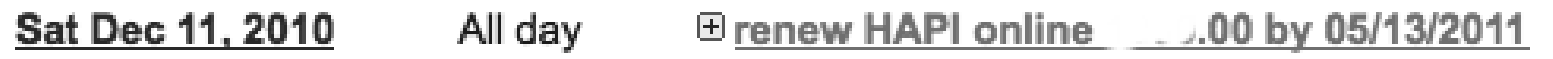

Wed Dec 15, 2010 All day $\boxplus$ renew Leadership library on the Internet

All day $\quad \Phi$ renew British humanities index BHI. .00 by $03 / 16 / 2011$

All day $\quad \pm$ renew Twentieth-century drama $\quad .00$ by $03 / 16 / 2011$

All day $\boxplus$ renew Twentieth century parliamentary papers .00 by 0

Fri Dec 17, 2010

All day $\boxplus$ renew CHANT (CHinese ANcient Texts) Han da wen ku.

All day $\boxplus$ renew Historical newspapers _..00 by 05/19/2011 
Figure 3. Search Results

twentieth Search my calendars Show search options

\begin{tabular}{|c|c|c|}
\hline Today & nday, Dec & 2010 \\
\hline \multicolumn{3}{|l|}{ « Back to calendar } \\
\hline \multirow[t]{2}{*}{ Wed Dec 15, 2010} & All day & $\boxplus$ renew Twentieth-century drama $\quad .00$ by $03 / 16 / 2011$ \\
\hline & All day & $\Phi$ renew Twentieth century parliamentary papers 385.00 by 0 \\
\hline \multirow[t]{3}{*}{$\underline{T u e ~ F e b ~ 22, ~} 2011$} & All day & $\Phi$ Twentieth-century drama $\_.00$ \\
\hline & All day & $\Phi$ Documents on British policy overseas diplomacy in the tw \\
\hline & All day & $\boxplus$ Twentieth century parliamentary papers $\quad \underline{.00}$ \\
\hline Fri Mar 4, 2011 & All day & \pm renew Twentieth century North American drama 250.00 by \\
\hline Thu Apr 7, 2011 & All day & $\boxplus$ Twentieth century North American drama $\quad .00$ \\
\hline Thu May 5, 2011 & All day & $\boxplus$ renew Twentieth century North American drama \\
\hline \multirow[t]{3}{*}{ Thu Sep 22, 2011} & All day & $\boxplus$ renew Documents on British policy overseas diplomacy \\
\hline & All day & $\boxplus$ renew Twentieth century parliamentary papers \\
\hline & All day & 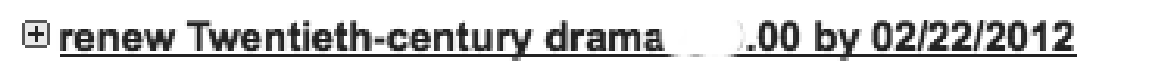 \\
\hline Sat Nov 5, 2011 & All day & $\boxplus$ renew Twentieth century North American drama \\
\hline \multirow[t]{3}{*}{ Wed Nov 23, 2011} & All day & $\boxplus$ renew Twentieth century parliamentary papers \\
\hline & All day & $\boxplus$ renew Twentieth-century drama \\
\hline & All day & $\boxplus$ renew Documents on British policy overseas diplomacy in \\
\hline Fri Jan 6, 2012 & All day & $\boxplus$ renew Twentieth century North American drama ..... \\
\hline
\end{tabular}


The follow-up discussion in February was designed primarily to elicit feedback from selectors who had actually made use of the fund calendars over the previous three months, and to provide those who were slow starters with some additional advice and prodding. A few enthusiastic users provided testimonials, and a quick demonstration was given to remind selectors where to go and how to use the system. Finally, workshop sessions were offered. These workshops not only covered the Google fund calendars but also provided a review of the basic functionality of our ERMS, an overview of electronic resource usage statistics as provided by vendors and as harvested and consolidated in our ERMS, and a discussion of overlap analysis. Together these topics comprised a basic toolkit enabling selectors to get started with the process of timely assessment.

To gauge the uptake of calendar use, the group checked to see just how many selectors had indeed subscribed to any of the fund calendars, via a script which is available online. (Carroll et al, 2011) As of January 13th, 2011, twenty-five individuals had subscribed to at least one fund calendar. Of this total, sixteen were selectors. The remaining subscribers, indicating the breadth of interest in this project, included division directors, Associate University Librarians, and members of Acquisitions. Within the Columbia University Library system, more than forty staff have selection responsibilities. These range from those whose primary duties consist of selection in combination with reference and liaison to those for whom selection constitutes only a relatively small part of their job responsibilities. Given that situation, sixteen selectors subscribing to at least one fund calendar at this early stage was seen as a good start. In July, the group decided to check in again on how many selectors had subscribed to the fund calendars. There were now twenty-three selectors who had subscribed to at least one fund calendar. The increase was positive, but still only about half of all selectors had subscribed.

Since we can specifically identify who is subscribed, we can focus on those selectors who have not subscribed to any fund calendar and begin to follow up with them. Some non-subscribers may be responsible for only a handful of ongoing electronic resource purchases and may not be convinced of the utility of the calendar. Following up with selectors who had subscribed has shown us many different use cases. Many of our selectors are relatively new to the assessment process and find it natural to receive 
renewal data in a calendar format and appreciate having that data pushed to them. On the other hand, selectors in some subject areas have a longer history when it comes to the assessment of electronic resource usage data and had successfully been using the existing systems. The sciences, for example, having moved to e-only journals as early as the late 1990s, have had more time to become familiar with the need of assessing resource usage and have more experience making decisions based upon the results of this assessment. It was therefore gratifying to see that $100 \%$ of the science selectors had subscribed and found the fund calendars useful. Even these experienced users previously found it difficult to gauge the proper time intervals for assessment, and appreciated the guidance the calendars offered with the three and five month renewal reminders. They too, like the less-experienced users, found the calendar layout more intuitive than the earlier Voyager exports in forecasting renewals. The early involvement of this group of selectors with a longer history of electronic resource assessment was taken as a sign of the usefulness of the new fund calendars. This continued follow up through discussion and workshops is still needed to refine the assessment process and how the fund calendars can help support it.

\section{Conclusion}

Any library that seeks to encourage the ongoing assessment of electronic resources is likely to find a highly variable range of practices among selectors in different disciplinary areas. At Columbia University Libraries, for example, we found that librarians in the sciences had long been used to assessing resources based on usage data, and "swapping out" lower use titles in favor of higher use ones within the restrictions set by large electronic journal packages. In areas such as the humanities and social sciences, usage data was less commonly employed. In order to bring all selectors onto a comparable playing field, we established in 2009 an Electronic Resources Assessment Working Group, which was charged with identifying and promoting the assessment tools available to us. Promotion included both educational outreach, in workshops and one-on-one sessions with Working Group members; and motivational presentations, from selectors who had used assessment tools successfully to improve online collections. Selectors caught on relatively quickly to the fact that usage data can mean a variety of things. For 
example, when it was proposed that all journal titles that had received zero usage for the last year on a specific platform be cancelled, one selector pointed out that one of the journal titles in question was nowhere linked from the libraries' Web site and requested further that the link be added and the usage data reassessed after another year.

Our "middleware" solution, connecting Voyager and Google Calendar with custom code, was possible not only because Columbia University Library employs its own programmers, but also because Google Calendar is so amenable to being programmed. While responsive ERMS providers may adopt customers' workarounds in upcoming software releases, even the most attentive provider will not be able to provide every function as every customer needs it. Further, perhaps not every function that customers need could be provided (or provided well) in a single piece of software. Northwestern University librarians, for example, desired to manipulate their data using the advanced features of Excel and Access. (GustafsonSundell, 2011). While an ERMS might be able to replicate some spreadsheet or query functionality, it is unlikely to ever be practical to replicate an entire full-featured application.

Therefore, the most urgently needed functions are ones that allow customers, both programmers and non-programmers, to move data into and out of their management systems, to connect those systems to a variety of software. ERMS providers often cast interoperability issues in terms of supporting libraryspecific standards like COUNTER for statistics management. (Grogg and Collins, 2011) However, this doesn't help the librarians who are using Access, Excel, or Google Calendar, and it doesn't address the need to move diverse kinds of information between library management systems. Librarians need access to raw data in order to make technology suit local needs. Non-programmers can use features like RSS feeds and RSS feed ingesters to move raw data from one system to another. Programmers appreciate more sophisticated APIs. Consumer software increasingly provides this kind of functionality - Google Calendar, for instance, can both display and export RSS data. Rather than developing highly specific and limited standards for LMS interoperability, LMS providers may wish to look to widely used consumer standards instead. Columbia's experience developing exports against Voyager's database backend paved 
the way for scripting Google Calendar, but ideally, schools without the same dedicated technical resources should be able to move their data between systems in the same way.

It's important to start with flexible technology because ultimately technology is much easier to change than people are. Before the implementation of Google Calendar, the Working Group had struggled to motivate selectors to regularly and systematically use the ERMS (SerialsSolutions 360 Resource Manager) for assessment. While the ERMS was useful to trained selectors once they were using it, it fell short in "workflow or communications management," an area in which many librarians have found ERMS in general to be deficient (Grogg and Collins, 2011). Google Calendar had the advantage of being a "push" technology, providing the selectors with reminders rather than requiring the selectors to come to it. Google Calendar was already in use by all staff, so it was possible to package a new function into existing, familiar software. Although Google Calendar will never provide the assessment capabilities of an ERMS, outsourcing the scheduling of the assessment to Google Calendar was intuitive and minimally disruptive to staff. Once the problem of promoting assessment was recast as a technology issue rather than a staff motivational issue, a solution was in sight. 


\section{References}

Carroll, J., Major, C., Tofanelli, J. (2011). E-resource Renewal Awareness: Using Google Calendar to Bring Selectors on Board. Poster presented at the Association of College and Research Libraries National Conference, Philadelphia, April 1, 2011. Retrieved from http://hdl.handle.net/10022/AC:P:9978

England, L. (2011). Electronic resources evaluation central: Using off-the-shelf software, web 2.0 tools, and libguides to manage an electronic resources evaluation process. Journal of Electronic Resources Librarianship, 23(1), 30-42. doi: 10.1080/1941126X.2011.551093

Grogg, J. E., \& Collins, M. (2011). Building a better ERMS. Library Journal (1976), 136(4), 22-6, 28.

Gustafson-Sundell, N. (2011). Think Locally: A Prudent Approach to Electronic Resource Management Systems. Journal of Electronic Resources Librarianship, 23(2), 126-141. doi: 10.1080/1941126X.2011.576955

Kyrillidou, M., \& Morris, S. (Eds.). (2011). ARL statistics 2008-09. Retrieved from http://www.arl.org/stats/annualsurveys/arlstats/arlstats09.shtml

Shapiro, S. (2010). Using Google Calendar as an Email Alert System for Electronic Resource Renewals. Journal Of Library Innovation, 1(1). Retrieved from http://www.libraryinnovation.org/article/view/23 